\title{
Aging of Cu-3 at\% Ti Alloys in Hydrogen Atmosphere: Influence of Hydrogen Pressure on Strength and Electrical Conductivity*1
}

\author{
Satoshi Semboshi ${ }^{1}$, Tomoya Nishida ${ }^{2, * 2}$ and Hiroshi Numakura ${ }^{2}$ \\ ${ }^{1}$ Institute for Materials Research, Tohoku University, Sendai 980-8577, Japan \\ ${ }^{2}$ Department of Materials Science, Osaka Prefecture University, Sakai 599-8531, Japan
}

\begin{abstract}
The influence of hydrogen pressure during isothermal aging on the mechanical strength, electrical conductivity, and microstructure of $\mathrm{Cu}$ 3 at\% Ti alloys was investigated under various hydrogen pressures from 0 to $0.8 \mathrm{MPa}$. The variation of hardness with aging time was not significantly different among all specimens aged under the hydrogen pressures. This is because the hardness is improved primarily by the precipitation strengthening of $\mathrm{Cu}_{4} \mathrm{Ti}$ particles, which is less affected by hydrogen pressure. The electrical conductivity increased more significantly for specimens aged under higher hydrogen pressure, due to a rapid reduction in the concentration of Ti dissolved in the matrix, which is attributed to the accelerated formation of $\mathrm{TiH}_{2}$. The conductivity at peak-hardness was improved by a factor of approximately 1.4 in the specimens aged at both 773 and $723 \mathrm{~K}$ under the highest hydrogen pressure, compared to that for the specimen aged in vacuum. Therefore, aging under high hydrogen pressure assisted in the significant improvement of both strength and electrical conductivity. [doi:10.2320/matertrans.D-MA201031]
\end{abstract}

(Received October 15, 2010; Accepted February 4, 2011; Published March 30, 2011)

Keywords: copper-titanium alloy, hydrogen, aging, hardness, electrical conductivity, microstructure, precipitate, transmission electron microscopy

\section{Introduction}

Among the various copper $(\mathrm{Cu})$ based alloys, age-hardenable $\mathrm{Cu}$-titanium (Ti) alloys are attractive as a substitute for $\mathrm{Cu}$-beryllium (Be) alloys, which pose the relatively high production costs and potential health hazards of Be. The mechanical strength of $\mathrm{Cu}$-Ti alloys is comparable to that of $\mathrm{Cu}-\mathrm{Be}$ alloys with good stress-relaxation behavior and higher thermostability. ${ }^{1-4)}$ However, $\mathrm{Cu}-\mathrm{Ti}$ alloys are inferior in electrical conductivity, due to the much larger contribution of Ti solute to the resistivity than Be ${ }^{5,6)}$ To extend the industrial applicability of $\mathrm{Cu}-\mathrm{Ti}$ alloys for electrical parts such as lead frames and connectors, it is strongly desirable to provide $\mathrm{Cu}$-Ti alloys with both high strength and high conductivity.

Semboshi and Konno recently reported that the conductivity of $\mathrm{Cu}-3$ at\% $\mathrm{Ti}$ alloy increases more significantly when aged at $773 \mathrm{~K}$ in a hydrogen pressure of $0.37 \mathrm{MPa}$ rather than aged in vacuum. ${ }^{7)}$ The increase was attributed to a reduction in the concentration of $\mathrm{Ti}$ dissolved in the matrix, as a result of the formation of the titanium hydride $\left(\mathrm{TiH}_{2}\right)$ phase. In a subsequent paper, the microstructure and mechanical properties of the alloy aged under the same conditions were reported. ${ }^{8)}$ During the early stage of aging, fine needleshaped precipitates of the $\mathrm{Cu}_{4} \mathrm{Ti}$ intermetallic phase are dispersed, similar to aging in vacuum. Upon further aging, the precipitation of $\mathrm{Cu}_{4} \mathrm{Ti}$ proceeds and $\mathrm{TiH}_{2}$ particles are spontaneously formed by the combination of diffused hydrogen with $\mathrm{Ti}$ in the matrix and in the $\mathrm{Cu}_{4} \mathrm{Ti}$ precipitates. The hardness was increased with aging time and exhibited a peak at 1 to $3 \mathrm{~h}$, which was essentially similar to the case of aging in vacuum. Recently, it was found that aging at a low

\footnotetext{
${ }^{*} 1$ This Paper was Originally Published in Japanese in J. JRI Cu 49 (2010) 144-148.

${ }^{* 2}$ Graduate Student, Osaka Prefecture University. Present address: JTEKT Corporation, Kashihara 634-8555, Japan
}

temperature was useful for improving both the strength and conductivity. ${ }^{9)}$ For example, aging at $673 \mathrm{~K}$ under the hydrogen pressure of $0.08 \mathrm{MPa}$ resulted in an increase of the conductivity at peak-hardness that was more than twice as high as that of the same alloy aged in vacuum, although a long time (ca. 1 month) was required.

In order to prepare $\mathrm{Cu}-\mathrm{Ti}$ alloys with high strength and high conductivity by aging in hydrogen atmosphere, it is important to control the microstructural evolution, such as precipitations of $\mathrm{Cu}_{4} \mathrm{Ti}$ and $\mathrm{TiH}_{2}$ phases. It is therefore required to understand the influence of hydrogen pressure during aging, in addition to aging temperature, because it must influence directly on the formation of the $\mathrm{TiH}_{2}$. In the present work, $\mathrm{Cu}-3$ at\% $\mathrm{Ti}$ alloys was isothermally aged under hydrogen pressures between 0 and $0.8 \mathrm{MPa}$ to clarify the influence on the resulting hardness and conductivity. The microstructure was also examined using transmission electron microscopy (TEM) and X-ray diffraction (XRD) to confirm the relationship between their microstructure and properties.

\section{Experimental Procedure}

A button ingot with a nominal composition of $\mathrm{Cu}-3 \mathrm{at} \% \mathrm{Ti}$ was prepared by arc-melting $99.99 \%$ pure copper and $99.99 \%$ pure titanium as raw materials in argon atmosphere. The ingot was annealed at $1073 \mathrm{~K}$ for $24 \mathrm{~h}$ in vacuum for homogenization. The ingots were cold-rolled and subsequently cut into plates measuring $50 \times 5 \times 0.8 \mathrm{~mm}^{3}$. The specimens were solution-treated at $1073 \mathrm{~K}$ for $12 \mathrm{~h}$ in vacuum and quenched in water. In order to remove the surface oxide layer, the specimens were ground with 2000 grade $\mathrm{SiC}$ paper, and then rinsed in acetone. The plates were aged at 773 and $723 \mathrm{~K}$ in vacuum or under hydrogen pressures of 0.08 to $0.8 \mathrm{MPa}$, using $99.99999 \%$ pure hydrogen gas. 
The Vickers hardness was examined with an applied load of $500 \mathrm{~g}$ and a holding time of $10 \mathrm{~s}$. The hardness number was determined by averaging the results of more than ten tests, excluding the maximum and minimum values. The electrical conductivity of the aged specimens was measured at room temperature using the standard DC four-probe technique. The hydrogen content of the specimens was analysed by the fusion thermal conductivity method with argon as carrier gas, ${ }^{10)}$ using a hydrogen analyzer HORIBA EMGA-621W. The microstructure of specimens aged at $773 \mathrm{~K}$ under hydrogen atmospheres of 0.2 and $0.5 \mathrm{MPa}$ was examined by TEM. Thin-foil samples for TEM observations were first ground to less than $80 \mu \mathrm{m}$ in thickness and then electropolished in a solution of 5.0 vol\% nitric acid in methanol at $243 \mathrm{~K}$ with a DC voltage of less than $10 \mathrm{~V}$, followed by lowangle ion milling with an argon ion beam accelerated at $3 \mathrm{kV}$. XRD patterns were obtained using $\mathrm{Cu} \mathrm{K} \alpha$ radiation. The lattice parameters were determined by extrapolating the values measured from the XRD profiles to $\theta=90$ degree as a function of $\cos ^{2} \theta$. The content of Ti dissolved in the matrix phase was estimated from the lattice parameter using Vegard's law. 7,11 )

\section{Results and Discussion}

\subsection{Hardness and electrical conductivity}

Figures 1(a) and (b) show the variations of hardness and electrical conductivity for the $\mathrm{Cu}-3$ at $\% \mathrm{Ti}$ alloys, respectively, during aging at $773 \mathrm{~K}$ in vacuum and under hydrogen pressures of 0.08 to $0.5 \mathrm{MPa}$. The results for specimens aged under the hydrogen pressure of 0.08 and $0.37 \mathrm{MPa}$ were taken from previous studies. ${ }^{7-9)}$ For all these hydrogen pressures, the hardness increased with aging time and then reached the maximum after 1 to $3 \mathrm{~h}$, although the hardness appeared to be only slightly lower by aging under higher hydrogen pressure (see Fig. 1(a)). Figure 1(b) shows that the conductivity increased more rapidly by aging under higher hydrogen pressure. The conductivity of the specimen aged under the hydrogen pressure of $0.5 \mathrm{MPa}$ reached approximately $70 \%$ IACS (\%IACS: percentage based on the electrical conductivity of the International Annealed Copper Standard at $298 \mathrm{~K}, 5.80 \times 10^{7} \Omega^{-1} \mathrm{~m}^{-1}$ ) after $48 \mathrm{~h}$, which was approximately four times as high as the maximum conductivity of the specimen aged in vacuum.

Figures 2(a) and (b) show the variations of the hardness and electrical conductivity, respectively, during aging at $723 \mathrm{~K}$ in vacuum and under hydrogen pressures of 0.08 to $0.8 \mathrm{MPa}$. The values of the specimen aged under the hydrogen pressure of $0.08 \mathrm{MPa}$ were taken from a previous study. ${ }^{8)}$ The variation of hardness and conductivity with aging time was substantially similar to that for aging at $773 \mathrm{~K}$; the aging time to reach the peak-hardness was almost the same, approximately $18 \mathrm{~h}$, for all the hydrogen pressures, whereas the hardness was slightly lower and the conductivity was higher when aged in higher hydrogen pressure.

Figures 3(a) and (b) show the variations of peak-hardness and conductivity at peak-hardness, respectively, with respect to the hydrogen pressure for aging at 773 and $723 \mathrm{~K}$. It should be noted that the values used were those for specimens aged for $3 \mathrm{~h}$ at $773 \mathrm{~K}$ and for $18 \mathrm{~h}$ at $723 \mathrm{~K}$. For aging both at 773
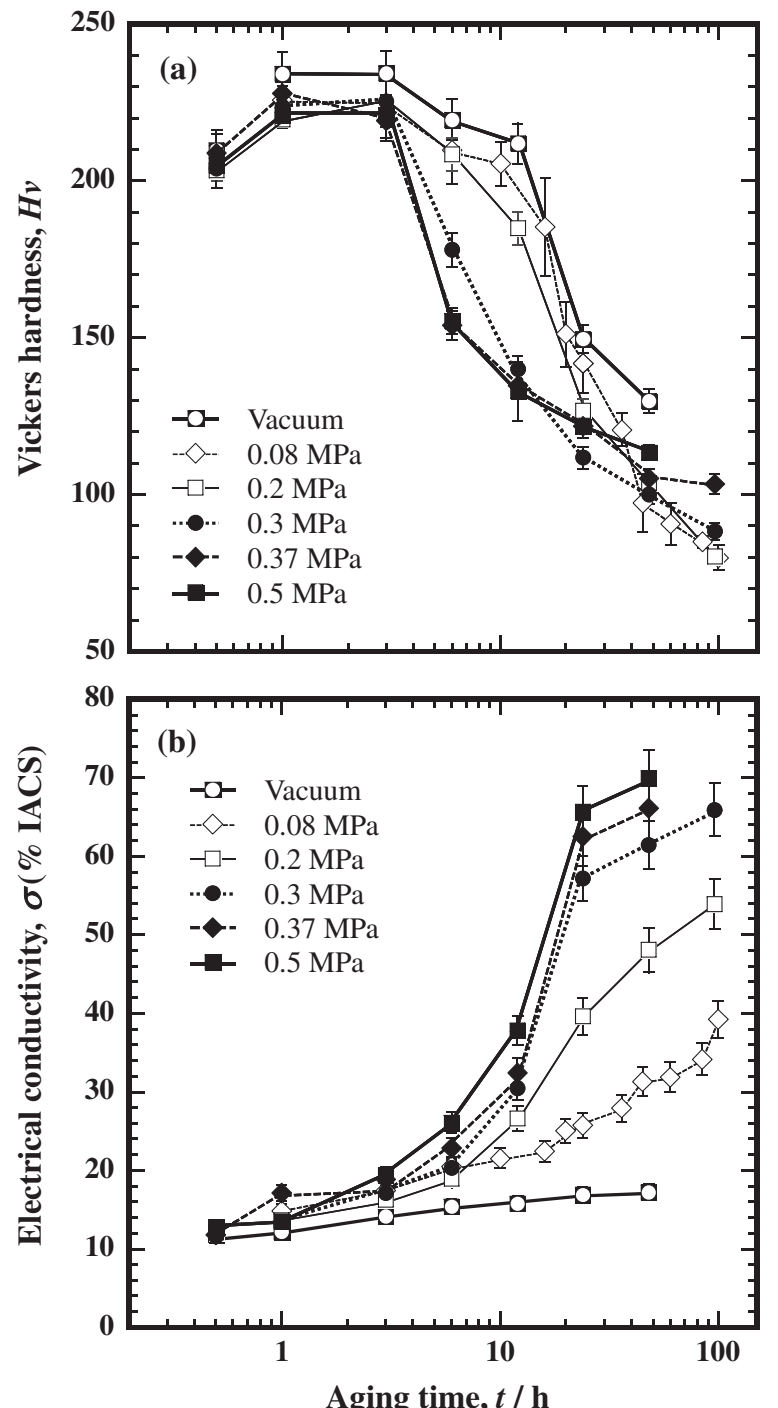

Fig. 1 Variations of (a) Vickers hardness and (b) electrical conductivity for $\mathrm{Cu}-3$ at $\% \mathrm{Ti}$ alloys aged at $773 \mathrm{~K}$ in vacuum, and under hydrogen pressures of $0.08,{ }^{9)} 0.2,0.3,0.37^{7,8)}$ and $0.5 \mathrm{MPa}$.

and $723 \mathrm{~K}$, the peak-hardness decreased gradually with increased hydrogen pressure, as shown in Fig. 3(a). However, the ratio of decrease was only within $6 \%$, based on the value of aging in vacuum. On the other hand, the conductivity at peak-hardness increased significantly with increased the hydrogen pressure, as shown in Fig. 3(b), and the ratio of increase was approximately $38 \%$ for the specimen aged at $773 \mathrm{~K}$ in the hydrogen pressure of $0.5 \mathrm{MPa}$ and approximately $43 \%$ for that aged at $723 \mathrm{~K}$ in $0.8 \mathrm{MPa}$. Therefore, it can be concluded that aging under high hydrogen pressure is available for improvement of both the peak-hardness and the conductivity at peak-hardness.

From a practical viewpoint, the peak-hardness and the conductivity at peak-hardness are the most important properties, because a high conductivity is required for age-hardenable $\mathrm{Cu}$-Ti alloys without degradation of the mechanical properties. It has been previously reported that aging at low temperature, $T$, was effective to improve both the strength and conductivity of $\mathrm{Cu}-\mathrm{Ti}$ alloys. ${ }^{8)}$ However, it takes a much longer time to achieve such by aging at a lower temperature, because the aging time to reach peak-hardness is proportional 

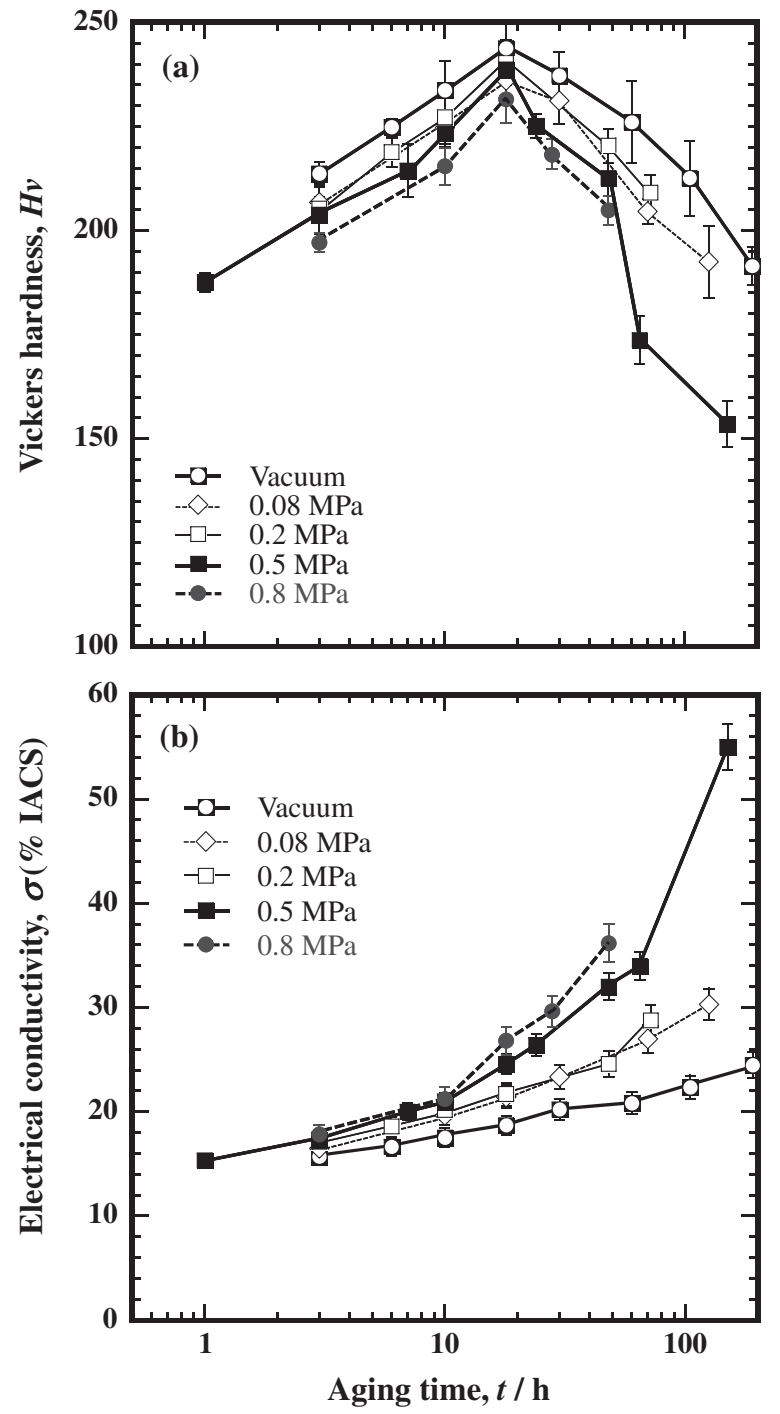

Fig. 2 Variations of (a) Vickers hardness and (b) electrical conductivity for $\mathrm{Cu}-3 \mathrm{at} \% \mathrm{Ti}$ alloys aged at $723 \mathrm{~K}$ in vacuum, and under hydrogen pressures of $0.08,{ }^{9)} 0.2,0.5$ and $0.8 \mathrm{MPa}$.

to $\exp \left(T^{-1}\right)$. In this study, we have demonstrated that aging in high hydrogen pressure can be used for improvement of the conductivity at peak-hardness of $\mathrm{Cu}$-Ti alloys, and that the aging time to reach the peak-hardness was not significantly altered with the hydrogen pressure. Therefore, an increase of the hydrogen pressure during aging is available to provide a reasonably good combination of both strength and conductivity, even if the aging temperature is not low.

\subsection{Microstructural evolution}

Figure 4 shows the hydrogen contents of specimens aged at $773 \mathrm{~K}$ in vacuum and under the hydrogen pressures of 0.2 , 0.37 and $0.5 \mathrm{MPa}$ for various aging times. The hydrogen contents of the specimen aged under a hydrogen pressure of $0.37 \mathrm{MPa}$ were taken from a previous study. ${ }^{7}$ The hydrogen contents of the specimens quenched and aged in vacuum were less than $0.01 \%$, whereas that of the specimen aged under a the hydrogen pressure of $0.2 \mathrm{MPa}$ increased with aging time and reach approximately 4.7 at $\%$ at $96 \mathrm{~h}$. The hydrogen content increased more rapidly for the specimens aged under higher hydrogen pressure.

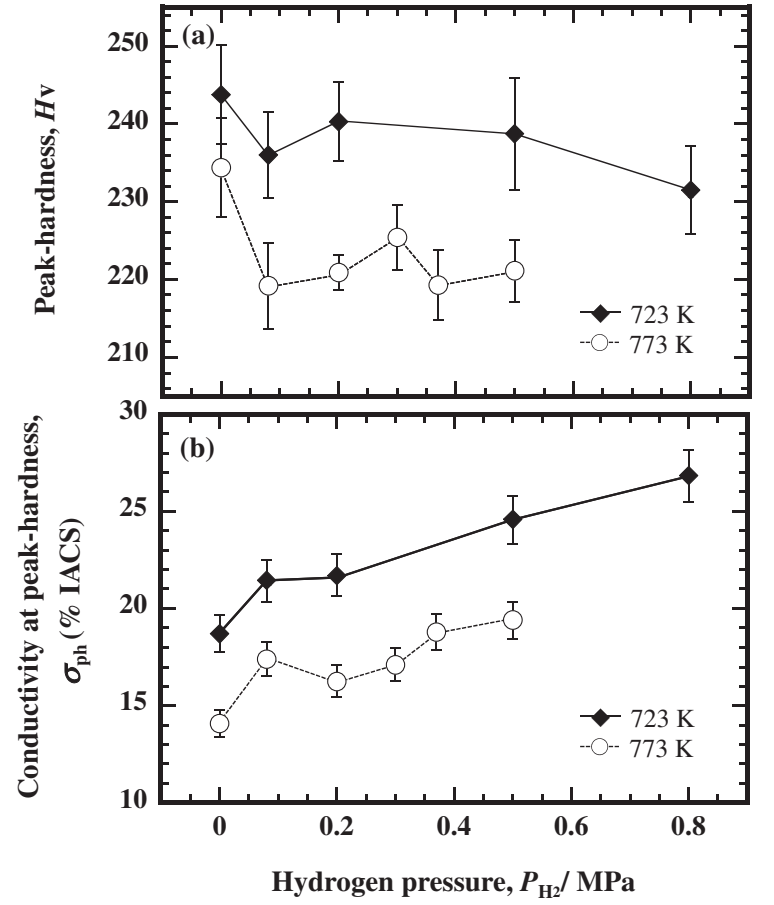

Fig. 3 Variations of (a) peak-hardness and (b) electrical conductivity at peak-hardness for $\mathrm{Cu}-3 \mathrm{at} \% \mathrm{Ti}$ alloys aged at 773 and $723 \mathrm{~K}$ under hydrogen pressure. The aging time to peak-hardness was $3 \mathrm{~h}$ at $773 \mathrm{~K}$ and $18 \mathrm{~h}$ at $723 \mathrm{~K}$.

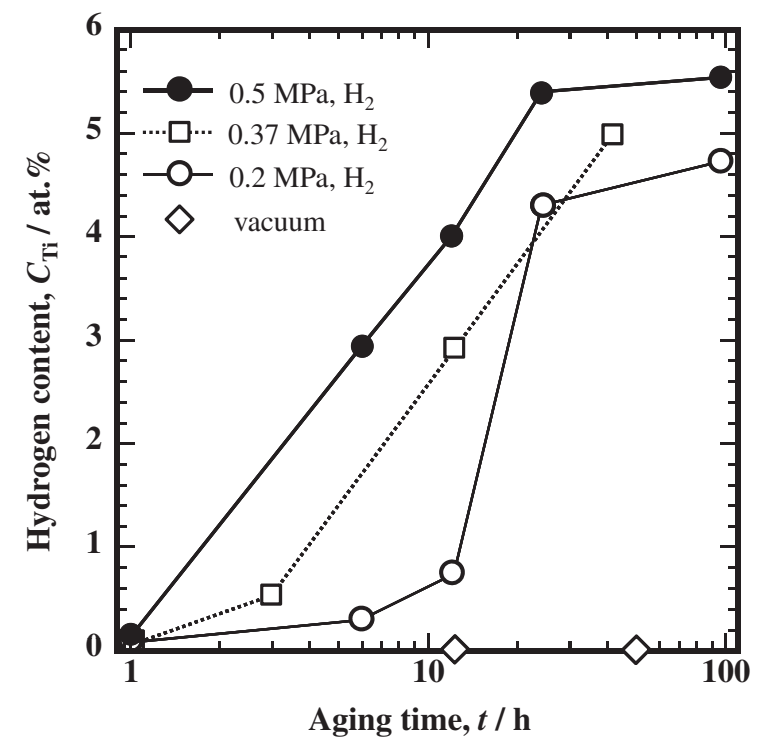

Fig. 4 Variation of hydrogen content in $\mathrm{Cu}-3$ at\% $\mathrm{Ti}$ alloys aged at $773 \mathrm{~K}$ in vacuum, and under hydrogen pressures of $0.2,0.37^{8)}$ and $0.5 \mathrm{MPa}$.

The microstructural evolution of a specimen aged at $773 \mathrm{~K}$ in a hydrogen atmosphere at $0.37 \mathrm{MPa}$ has been investigated ${ }^{8)}$ finely dispersed precipitates of $\mathrm{Cu}_{4} \mathrm{Ti}$ were formed during the early aging stage, and subsequently particles of titanium hydride, $\mathrm{TiH}_{2}$, were also formed by reaction of dissolved hydrogen atoms with $\mathrm{Ti}$ atoms in the matrix or in $\mathrm{Cu}_{4} \mathrm{Ti}$ precipitates. The precipitation behavior of $\mathrm{Cu}_{4} \mathrm{Ti}$ was similar to the specimens aged at the same temperature of $773 \mathrm{~K}$ under the hydrogen pressures of 0.2 to $0.5 \mathrm{MPa}$, whereas the formation of $\mathrm{TiH}_{2}$ was promoted by increasing the hydrogen pressure for aging, as described below. 


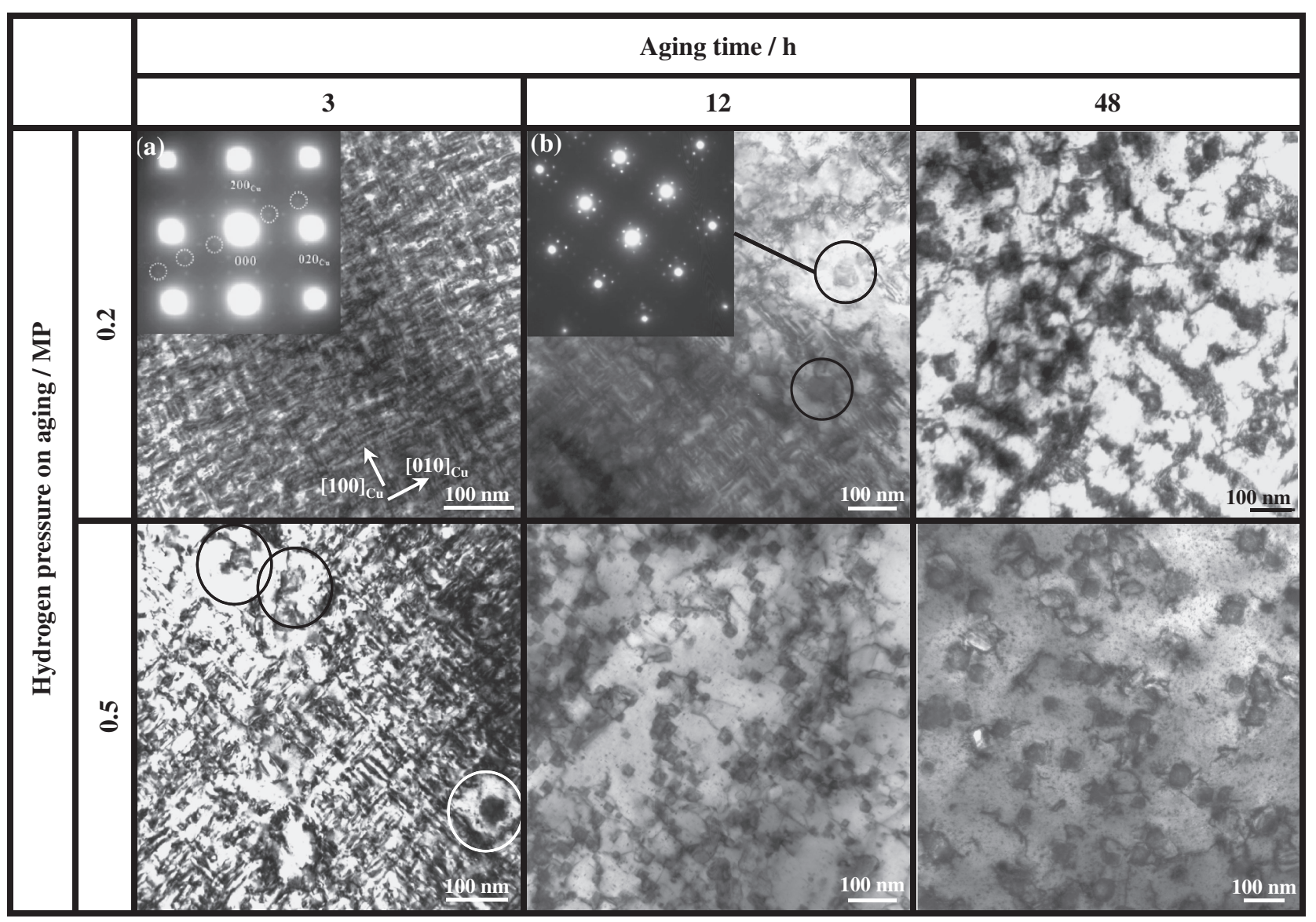

Fig. 5 Bright field transmission electron microscope (BF TEM) images and selected area diffraction (SAD) patterns viewed along the [001] zone axis for $\mathrm{Cu}-3$ at $\% \mathrm{Ti}$ alloys aged at $773 \mathrm{~K}$ for 3, 12, and $48 \mathrm{~h}$ under hydrogen pressures of 0.2 and $0.5 \mathrm{MPa}$. The weak spots marked by dotted circles in (a) are those in the 001 diffraction pattern of $\mathrm{Cu}_{4} \mathrm{Ti}$. The weak spots shown in (b) are from $\mathrm{TiH}_{2}$, which was taken from the rhombic contrast, and representative examples are indicated by solid circles in the BF TEM image.

Figure 5 shows bright field (BF) TEM images and selected area diffraction (SAD) patterns of specimens aged at $773 \mathrm{~K}$ for 3,12 , and $48 \mathrm{~h}$ under hydrogen pressures of 0.2 and $0.5 \mathrm{MPa}$. The BF TEM imaged of the specimen aged for $3 \mathrm{~h}$ under the hydrogen pressure of $0.2 \mathrm{MPa}$ is dominated by characteristic needle-shaped contrasts aligned in the $\langle 001\rangle_{\mathrm{Cu}}$ directions. The contrasts are due to coherency misfit strain arising from $\mathrm{Cu}_{4} \mathrm{Ti}$ precipitates (space group $I 4 / m$ with lattice parameters $a=0.584 \mathrm{~nm}, c=0.362 \mathrm{~nm}^{1,4,12)}$ ), which was confirmed by the corresponding SAD pattern. On aging at $12 \mathrm{~h}$, the BF TEM image shows coarsened needle-shaped $\mathrm{Cu}_{4} \mathrm{Ti}$ precipitates of approximately $100 \mathrm{~nm}$ in length, and rhombic contrasts of approximately $50 \mathrm{~nm}$ in size, as indicated by the solid circle. The latter is attributed to $\mathrm{TiH}_{2}$ $\left(F m \overline{3} m\right.$ with $\left.a=0.444 \mathrm{~nm}^{13,14)}\right)$ as identified by the SAD pattern. On aging at $48 \mathrm{~h}$, some needle-like $\mathrm{Cu}_{4} \mathrm{Ti}$ precipitates of more than $100 \mathrm{~nm}$ in length were present, but rhombic $\mathrm{TiH}_{2}$ particles of approximately $50 \mathrm{~nm}$ were predominant in the specimen. On the other hand, for the specimen aged under the hydrogen pressure of $0.5 \mathrm{MPa}$, rhombic $\mathrm{TiH}_{2}$ particles were already formed together with needle-shaped $\mathrm{Cu}_{4} \mathrm{Ti}$ after $3 \mathrm{~h}$. On further aging after $12 \mathrm{~h}$, only rhombic contrasts due to $\mathrm{TiH}_{2}$ were observed in the $\mathrm{Cu}$ matrix phase, which suggests that almost all of the $\mathrm{Cu}_{4} \mathrm{Ti}$ precipitates were decomposed to $\mathrm{TiH}_{2}$ and $\mathrm{Cu}$ during the earlier period of aging than in the case of hydrogen pressure of $0.2 \mathrm{MPa}$.

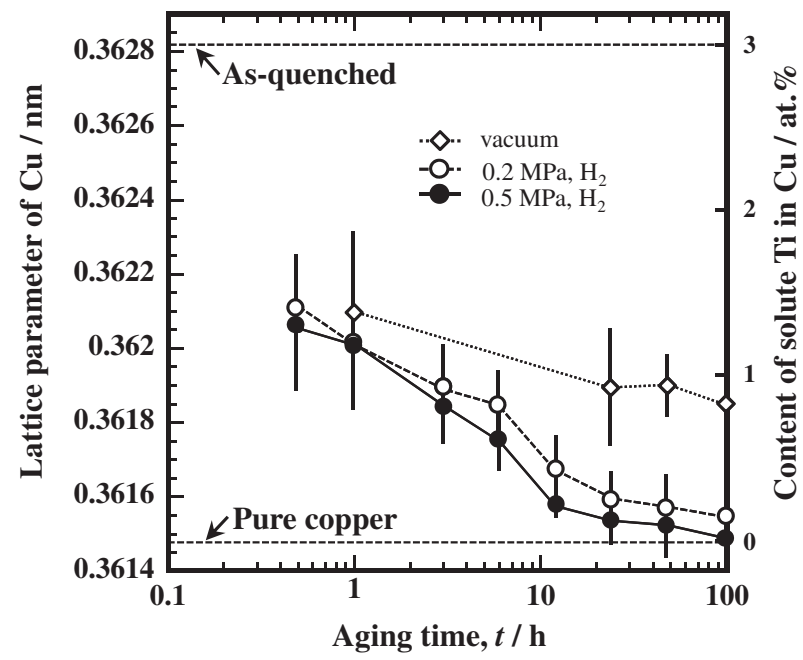

Fig. 6 Lattice parameters and Ti solute content in the $\mathrm{Cu}-3$ at\% $\mathrm{Ti}$ alloy matrix aged at $773 \mathrm{~K}$ in vacuum and under hydrogen pressures of 0.2 and $0.5 \mathrm{MPa}$. The lattice parameters of pure copper and as-quenched $\mathrm{Cu}-3$ at $\%$ Ti specimen were 0.3615 and $0.3628 \mathrm{~nm}$, respectively.

Figure 6 shows the lattice parameters and Ti content in the matrix estimated from the lattice parameters of specimens aged at $773 \mathrm{~K}$ in vacuum and under hydrogen pressures of 0.2 and $0.5 \mathrm{MPa}$ for various aging times. The lattice parameters 
of the specimens decreased with aging time, with an equivalent decrease in the content of $\mathrm{Ti}$ in the matrix. After $24 \mathrm{~h}$ aging in vacuum, the Ti content in the matrix remained at approximately 0.8 at $\%$, which agrees well with the solid solubility limit at $773 \mathrm{~K}$ evident from the $\mathrm{Cu}$-Ti binary phase diagram. ${ }^{15)}$ When aged in a hydrogen atmosphere, the Ti content in the matrix decreased significantly and rapidly under higher hydrogen pressures, due to the accelerated formation of $\mathrm{TiH}_{2}$.

\subsection{Effects of hydrogen pressure on aging}

The effect of hydrogen pressure during aging on the hardness and conductivity of the specimens can be explained by the microstructural evolution; the hardness of the specimen should be modelled by the superposition of solid solution hardening and precipitation hardening of $\mathrm{Cu}_{4} \mathrm{Ti}$ and $\mathrm{TiH}_{2}$ particles. During the early stage of aging, hardening of the specimen is primarily due to precipitation of $\mathrm{Cu}_{4} \mathrm{Ti}$, which progresses independently of the hydrogen pressure used. Therefore, the aging time to attain maximum hardness is less affected by the hydrogen pressure. On the other hand, the formation of $\mathrm{TiH}_{2}$ particles with further aging is accelerated by an increase of hydrogen pressure as indicated in Fig. 5, which leads to a rapid reduction of the Ti content in the matrix and the rapid decomposition of pre-formed $\mathrm{Cu}_{4} \mathrm{Ti}$ particles. Therefore, hardening by solid solution and by precipitation of $\mathrm{Cu}_{4} \mathrm{Ti}$ becomes weakened in a specimen aged under a higher hydrogen pressure, although hardening due to the precipitation of $\mathrm{TiH}_{2}$ emerges. The total amount of hardening should be eventually decreased by aging under a high hydrogen pressure, which would result in a slight decrease of hardness, as shown in Fig. 3(b). In addition, the significant reduction in the $\mathrm{Ti}$ concentration in the matrix by precipitation of $\mathrm{TiH}_{2}$ directly contributes to the marked increase in the conductivity of the specimen, which obeys Nordheim's rule;11,16) therefore, the conductivity increases more significantly with higher hydrogen pressure.

\section{Conclusion}

The effect of hydrogen pressure (0 to $0.8 \mathrm{MPa}$ ) during isothermal aging on the hardness and electrical conductivity of $\mathrm{Cu}-3$ at\% $\mathrm{Ti}$ alloys was investigated, together with the microstructural evolution. The salient results obtained are summarized as follows.

(1) The aging time to attain a maximum hardness was almost the same for all of the specimens aged at the same temperature, regardless of the hydrogen pressure. The hardness decreased slightly, whereas the conductivity increased significantly with increasing hydrogen pressure. As a result, aging in a high hydrogen pressure led to a significant improvement of both the mechanical and electrical properties.

(2) During the early stage of aging, fine needle-shaped $\mathrm{Cu}_{4} \mathrm{Ti}$ precipitates were dispersed in the matrix, which were little affected by the hydrogen pressure. As the aging progressed, $\mathrm{Cu}_{4} \mathrm{Ti}$ was precipitated and $\mathrm{TiH}_{2}$ particles were spontaneously formed by the combination of diffused hydrogen with $\mathrm{Ti}$ in the matrix and in $\mathrm{Cu}_{4}$ Ti precipitates. The formation of $\mathrm{TiH}_{2}$ particles was promoted by aging under high hydrogen pressure and resulted in a rapid reduction of $\mathrm{Ti}$ content in the matrix.

\section{Acknowledgement}

The authors thank Dr. K. Takada, Dr. T. Ashino and Mr. M. Ishiguro of the Institute for Materials Research (IMR) of Tohoku University for performing the hydrogen analyses, and Professors S. Hanada, T. J. Konno, N. Masahashi and S. Orimo, IMR for useful discussions and comments. This work was partly performed under the co-operative research program of Advanced Research Center of Metallic Glasses, IMR of Tohoku University. Financial support provided by the Inamori Foundation, the Japan Research Institute for Advanced Copper-based Materials and Technologies, the New Energy and Industrial Technology Development Organization (NEDO), and the Japan Science and Technology Agency (JST) is gratefully acknowledged.

\section{REFERENCES}

1) A. Datta and W. A. Soffa: Acta Metall. 24 (1976) 987-1001.

2) S. Nagarjuna, M. Srinvivas, K. Balasubramanian and D. S. Sarma: Acta Metall. 44 (1996) 2285-2293.

3) S. Nagarjuna, M. Srinvivas, K. Balasubramanian and D. S. Sarma: Scr. Mater. 18 (1998) 1469-1474.

4) W. A. Soffa and D. E. Laughlin: Prog. Mater. Sci. 49 (2004) 347-366

5) S. Nagarjuna, K. Balasubramanian and D. S. Sarma: Mater. Sci. Eng. A 225 (1997) 118-124.

6) S. Suzuki, K. Hirabayashi, H. Shibata, K. Mimura, M. Isshiki and Y. Waseda: Scr. Mater. 48 (2003) 431-435.

7) S. Semboshi and T. J. Konno: J. Mater. Res. 23 (2008) 473-477.

8) S. Semboshi, T. Nishida and H. Numakura: Mater. Sci. Eng. A 517 (2009) 105-113.

9) S. Semboshi, T. Nishida, H. Numakura, T. Al-Kassaab and R. Kirchheim: Metall. Mater. Trans. A in press.

10) A. Colombo: Anal. Chim. Acta 72 (1974) 401-406.

11) W. E. Krull and R. W. Newman: J. Appl. Cryst. 3 (1970) 519-521.

12) T. J. Konno, R. Nishio, S. Semboshi, T. Ohsuna and E. Okunishi: J. Mater. Sci. 43 (2008) 3761-3768.

13) S. B. Qadri, E. F. Skelton, M. Nagumo, A. W. Webb, F. E. Lynch and R. W. Marmaro: Phys. Rev. B 49 (1992) 1193-1194.

14) W. E. Wang: J. Alloy. Compd. 238 (1996) 6-12.

15) J. Y. Brun, S. J. Hamar-Thibault and C. H. Allibert: Z. Metallkd. 74 (1983) 525-529.

16) J. Miyake and M. E. Fine: Acta Metall. 40 (1992) 733-741. 